\title{
A Remote Sensing and Machine Learning Based Framework For The Assessment of Spatiotemporal Water Quality Along The Middle Ganga Basin
}

Ashwitha Krishnaraj ( $\nabla$ ashwitha.ashi@gmail.com )

National Institute of Technology Karnataka https://orcid.org/0000-0002-7595-0516

Ramesh H

National Institute of Technology Karnataka

\section{Research Article}

Keywords: River water quality, Machine learning, XGBoost regressor, MLP regressor, Hyperparameter optimization, Optuna, Gridsearch CV

Posted Date: December 21st, 2021

DOI: https://doi.org/10.21203/rs.3.rs-1093580/v1

License: (c) (i) This work is licensed under a Creative Commons Attribution 4.0 International License. Read Full License 


\section{Abstract}

Exploring qualitative measures of any waterbody is as vital as quantitative analysis for the sustainability of our water resources. Thus, examining the dynamics of spatiotemporal behaviour of dominant Water Quality Parameters (WQPs) along any waterbody is indeed critical for proposing the appropriate water resource management. This study aims to create a Machine learning model for mapping the dominant optical and non-optical WQPs such as Electrical Conductivity (EC), $\mathrm{pH}$, Temperature (Temp), Total Dissolved Solids (TDS), Silicon Dioxide (SiO2) and Dissolved Oxygen (DO) using satellite data. However, the association between WQPs and satellite data is strenuous to model precisely using simple regression theory.

In this context, we developed remote sensing-based Extreme Gradient Boosting (XGBoost) and Multilayer Perceptron (MLP) regressor with optimized Hyperparameters to understand the spatiotemporal variations of WQPs using Landsat-8 imageries. We evaluated six years of satellite data for the geographical area covering from Ankinghat to Chopan (20 sampling stations under Central Water Commission (CWC), Middle Ganga Division (MGD) II) for characterizing the trends of dominant Physico-chemical WQPs across the four clusters identified in our previous study. Through the developed XGBoost and MLP regression models between measured WQPs and the remote sensing reflectance for the pixels corresponding to the sampling stations, a significant coefficient of determination (R2) in the range of $0.88-0.98$ for XGBoost and 0.72-0.97 for MLP have generated with bands B1-B4 and their ratios more consistent. Indeed, our findings recommend fewer in-situ measurements to generate reliable Landsat-8 based ML models to estimate Spatio-temporal variations of Physico-chemical and biological WQPs to facilitate better management of our waterbodies.

\section{Introduction}

Surface water quality is vital in controlling coastal and riverine ecosystems, impacting water resources and human health. The foreseen impact of scare water and water quality (WQ) is the biggest challenge in this 21st century, especially in developing countries. As per the reports published by the International Water Management Institute, about $30 \%$ of the worlds total population is suffering to get clean water (Antonini et al., 2017). Therefore, keeping our surface water clean is of utmost importance, which requires in-depth knowledge of changing water quantity and quality (Chen et al., 2016; Nguyen et al., 2018). However, in-situ measurements of WQPs are usually limited, specifically in spatiotemporal domains, considering the costly data collection and laboratory analysis (Panda et al., 2004). Remote Sensing (RS) techniques have emerged as a widely accepted technology for carrying research in the domain of complex water resource systems. Due to the coverage, efficiency, and costly traditional laboratory sampling methods, the fast-developing environmental information technology and RS techniques have played eloquently in WQ monitoring. Since the 1970s, many number of satellites launched with multi-sensors onboard are continuously providing data. Satellite RS is a promising tool for assessing spatiotemporal alteration in WQ (Bonansea et al., 2015; El Saadi et al., 2014; Glasgow et al., 2004; Liu et al., 2015; Zhou et al., 2017) along coastal, inland and estuarine water bodies (González-Márquez et al., 2018; Vander Woerd \& Pasterkamp, 2004; Yepez et al., 2018). The different modelling techniques can study the changes caused in the electromagnetic spectrum of reflected radiation by the optically active water constituents (Haji Gholizadeh et al., 2016; Koponen et al., 2002; Teodoro et al., 2007; Wen \& Yang, 2009). Precisely, the modelling techniques determine the valid association between Remote sensing reflectance (Rrf) at different bands/band combinations with the in-situ WQPs (Panda et al., 2004; Sharaf El-Din et al., 2017a). The studies (Abdelmalik, 2018a; Allee \& Johnson, 1999; Andrzej Urbanski et al., 2016; Baban, 1993; Bonansea et al., 2018) described the usefulness of continuous WQ monitoring programmes. Research surveys showed that most studies utilized RS and regression-based modelling to estimate WQPs, especially optically active parameters. Theoretically, the dynamics of river WQ is highly complex to have a linear relationship with Rrf values (Xiang et al. 2016). Moreover, it is unlikely for simple regression-based techniques to model such a complex relationship, particularly the non-optical parameters (Sharaf El-Din et al., 2017b). The best band or combinations suggested predicting WQPs differ from one study to another due to the optical challenges of turbid waters. Besides, the transferability of these algorithms to other study environments remains uncertain from the papers reviewed. As far the sensors are concerned, the Landsat series has remained a popular choice, could be due to the free access and longest-running on-orbit (Xiaoyan Wang \& Yang, 2019) 
Machine learning $(\mathrm{ML})$ is the art of programming the computer the machine to learn from the data, in other words, training the machine or computer without being explicitly programmed. ML algorithms can automatically identify the existing rule from the data and predict the unknown data (Du et al., 2018). Many different ML algorithms are available nowadays; one can choose the best based on the required results and available data. It is observed that, in the domain RS of inland water, ML algorithms including artificial neural networks (ANN) (Liu et al., 2015; Sharaf El-Din et al., 2017a; Teodoro et al., 2007), genetic algorithms/programming (GA/GP) (Chang et al., 2012; Lounis et al., 2013; Swain \& Sahoo, 2017b), support vector machines (SVM) (Li et al., 2018; Xili Wang et al., 2010), random forest (RF)/boosted regression trees (Hafeez et al., 2019), have shown promising results in a spatiotemporal scales.

This research focused on proposing a best learning-based model with an appropriate number of input parameters (RS band data) for estimating the optically active and non-active WQPs from the Landsat-8 data.

The objectives of our research paper include (1) evaluation of two ML models, including ANN-based MLP and XGBoost regression, in-situ WQ data and satellite-derived Rrf data (Landsat-8) for WQ prediction along the selected inland waterbody.

(2) Delineate spatial maps for the predicted WQPs. As the chosen area of interest has 20 WQ stations, to minimize the complexity of the model in many aspects, the results from the study conducted and published (Krishnaraj \& Deka, 2020) are considered. Hereafter, the study results are discussed based on the identified Clusters instead of individual sampling stations and dominant WQPs (E.C., pH, Temp, TDS, SiO2 and DO causing Spatio-temporal variations) for further analysis.

\section{Materials And Methods}

The section here explains the methodologies in detail with four main Sections in which 1st Explains the study area selected and the list of clusters and WQPs chosen from the previous study. 2nd Satellite data, 3rd Modelling of WQPs using different Machine Learning algorithms: We have discussed feature selection method for the modelling, ANN-MLP and XGBoost regression algorithms, and hyperparameter optimization adopted for the study. The remote sensing part adopted in this study has included in Fig. 1.

\section{Study Area}

The Ganga River Basin (GRB) is a portion of the composite Ganga-Brahmputra-Meghna basin that lies in India, Bangladesh, China, and Nepal (drainage area1,086,000 sq. km). The basin area of 861,000 sq. km, i.e., approximately $80 \%$, flows in different parts of India (Trivedi, 2010). GRB covers approximately $26 \%$ of India's landmass and keep up $43 \%$ of its population (448.3 million as per the 2001 census) (River \& Management, 2013). Annual average rainfall along the basin ranges from $39-200 \mathrm{~cm}$ (average $110 \mathrm{~cm}$ ). $80 \%$ of this receives in June to October, i.e. wet season or monsoon months. Large temporal fluctuations are observed in precipitation over the years, which causes fluctuations in the river flow (Namami Gange, 2020).

In GRB, nearly 12,000 million litres/day ( $\mathrm{mld}$ ) sewage is generated for a treatment capacity of against $4000 \mathrm{mld}$. It is noted that the Class I \& II cities situated along the banks of the river is discharging approximately $3000 \mathrm{mld}$ sewage, although the treatment capacity is approximately $1000 \mathrm{mld}$ (Namami Gange, 2020). Many studies have confirmed the alarming rate of urbanization, industrialization, and so the strong demand poses a severe threat to river WQ. Some of its stretches between Kannauj to Allahabad, nearly $350 \mathrm{~km}$ along the basin, are worst affected (Annual Report 2006). Kanpur city is famous for its leather and textile industries, WQ of the river worsens after this city. Therefore, the turbidity of the river along this stretch becomes low to moderate (Garg et al., 2020). Varanasi is another crucial major city of UP known for its silk fabrics, ivory, perfumes, and sculpture industries.

In this study, the in-situ data are collected from MGD I\&II, CWC, India, for the 20 sampling stations situated across Uttara Pradesh(UP) with a popluation of around 200 million (199,581,477 as per Census 2011). This Indian state is the most populous sub-national entity (River \& Management, 2013). It covers $236,286 \mathrm{sq} . \mathrm{km}$ and lies within latitude $24^{\circ}$ to $31^{\circ} \mathrm{N}$ and 
longitude $77^{\circ}$ to $84^{\circ} \mathrm{E}$, lies along the banks of highly fertile and populated middle to upper Gangetic plains. A cited before in our previous study, and we identified the most significant WQPs which is causing the spatiotemporal changes in river WQ along the study area are identified using Principal Component Analysis (PCA) on an extensive data set (20 WQPs collected from 2005-2018 monthly) as listed in (Table 1). The location of the study area and the distribution of WQ sampling stations along the study area are shown in Fig. 2 and 3, respectively.

Table 1

Selected WQPs in the study

\begin{tabular}{|ll|}
\hline Parameter & Description \\
\hline $\begin{array}{l}\text { Electrical } \\
\text { conductivity(EC) }\end{array}$ & $\begin{array}{l}\text { The measure of water's ability to pass electricity. This ability depends on the concentrations of } \\
\text { ions in the water. }\end{array}$ \\
\hline $\mathrm{PH}$ & $\begin{array}{l}\text { It indicates how acidic or basic the water is on a scale of } 0-14 \text {. It is the percentage of hydrogen } \\
\text { ion concentration }\end{array}$ \\
\hline $\begin{array}{l}\text {-Total dissolved } \\
\text { solids(TDS) }\end{array}$ & $\begin{array}{l}\text { It is the minerals, salts, metals dissolved in the water. Typically, in the range of } 50 \text { to } 250 \mathrm{mg} / \mathrm{L} \\
\text { for lakes and streams. }\end{array}$ \\
\hline $\begin{array}{l}\text { Temperature(Temp) } \\
\text { It has a significant influence on biological activities, water chemistry and can influence WQ } \\
\text { measurements and controls the kinds of organisms that live in water bodies. }\end{array}$ \\
\hline $\begin{array}{l}\text { Silicon } \\
\text { Dioxide(SiO2) }\end{array}$ & $\begin{array}{l}\text { Silica is a major component of sand, and it's part of various minerals. Water is near to sediments } \\
\text { contains more silicon than the sea surface. }\end{array}$ \\
\hline $\begin{array}{l}\text { Dissolve Oxygen } \\
\text { (DO) }\end{array}$ & $\begin{array}{l}\text { Important physicochemical parameter, DO level that is too high or too low can harm aquatic life } \\
\text { and affect WQ. Correlates with many other WQPs. }\end{array}$ \\
\hline
\end{tabular}


Table 2 Spatial grouping of WQ monitoring stations for Dry and Wet seasons (Krishnaraj \& Deka, 2020)

\begin{tabular}{|c|c|c|c|}
\hline Station Number & Stations & Dry season grouping & Wet season grouping \\
\hline 0 & Allahabad & 1 & 3 \\
\hline 1 & Ankinghat & 3 & 1 \\
\hline 2 & Ayodhya & 2 & 2 \\
\hline 3 & Balrampur & 2 & 2 \\
\hline 4 & Basti & 2 & 2 \\
\hline 5 & Bhitaura & 3 & 1 \\
\hline 6 & Birdghat & 2 & 2 \\
\hline 7 & Chopan & 0 & 0 \\
\hline 8 & Duddhi & 0 & 0 \\
\hline 9 & Elginbridge & 2 & 2 \\
\hline 10 & Kanpur & 3 & 1 \\
\hline 11 & Lucknow & 3 & 1 \\
\hline 12 & Maighat & 1 & 3 \\
\hline 13 & Maeja & 0 & 0 \\
\hline 14 & Mirzapur & 1 & 3 \\
\hline 15 & Raebareli & 3 & 1 \\
\hline 16 & Shahzadpur & 1 & 3 \\
\hline 17 & Sultanpur & 1 & 3 \\
\hline 18 & Turtipar & 2 & 2 \\
\hline 19 & Varanasi & 1 & 3 \\
\hline
\end{tabular}

\section{Satellite Data}

The images selected for any WQ correlation study must be collected within a day of an in-situ sampling event. However, many researchers have suggested a window of up to seven days (Barrett \& Frazier,2016; Song et al., 2020) and 3-10 days as acceptable (Andrzej Urbanski et al., 2016). We decided to incorporate images downloaded within a five-day timeframe (before or after) of the sampling event in this study. The acquired Landsat-8 OLI data for cloud-free dates from 2014-2019 were preprocessed for radiometric and atmospheric corrections, as it is essential for retrieving qualitative data from RS imageries (Abdelmalik, 2018b; Bay et al., 2017). The atmospheric correction is applied using FLAASH module of ENVI (Exelis Visual Information Solutions, Inc. Boulder, USA) (Abdelmalik, 2018b; Olmanson et al., 2013; Yepez et al., 2018). FLAASH, as a first-principle atmospheric correction algorithm capable of correcting the wavelengths from visible to nearinfrared and shortwave infrared regions by up to $3 \mu \mathrm{m}$ (Garg et al., 2017). It incorporates the MODTRAN 4 radiation transfer code. FLAASH is widely used to remove the atmospheric errors and transform the spectral radiance of RS images to the surface reflectance of water. The accuracy of this preprocessed multispectral imagery is then compared using the ground control points (Liu et al., 2015). Finally, the water images are extracted by applying the Normalized Difference Water Index (NDWI) in ENVI 5.3. 


\section{Modelling of WQPs using different Machine Learning algorithms XGBoost modelling}

Extreme Gradient Boosting is the application of gradient boosting machines (GBM), known for their suitability to perform supervised learning (Ibrahem et al., 2021), that uses the boosting ensemble learning algorithm principles to predict the outcomes (Kiangala \& Wang, 2021). A detailed explanation is carried out in this research paper. These ensemble models are created using a decision tree, where trees are added one at a time to the ensemble and then correct the prediction errors made by previous models. This type of ensemble machine learning model referred to as boosting can be applied for regression and classification problems. The properties such as the requirement of lesser sample for the learning processes, fast training, fewer parameters to adjust, mathematical explanation and data processing of tabular format are some of the advantages of XGBoost (Profiles, n.d.).

The procedure of constructing XGBoost consists of assembling a base model for an existing model, i.e., training an initial tree, then it will construct a second tree combined with the initial tree, and repeat the second step until the expected number of trees is reached (Zhang et al., 2020). The principle behind this algorithm is to develop the new base-learners to maximally correlate with the negative gradient of the loss function associated with the whole ensemble. The loss functions applied can be random, but in a classic squared-error loss, the learning procedure would result in consecutive error-fitting (Natekin \& Knoll, 2013). XGBoost is designed as a highly scalable and accurate tree boosting system. Most XGBoost enhancements focus on taking full advantage of computing and memory capacities to speed up the learning process to the maximum (González et al., 2020). Besides, XGBoost also includes necessary adaptations to reduce over-fitting and to extend its use to all types of problems. The main feature against over-fitting is its regularized model formalization. Three gradient boosting techniques can be performed by XGBoost: Regularized Boosting, Stochastic Boosting, and Gradient Boosting. This algorithm benefits from using memory resources optimally and effectively treating the missing values during the training process. To approximate the goals, XGBoost adopts the Taylor expansion:(González et al., 2020). XGBoost objective function includes a regularization term that controls the complexity of the model. This addition allows to learn simple and predictive models and find a good bias-variance trade-off.

\section{Multi-Layer Perceptron (MLP)}

The MLP is a feed-forward neural network (FFNN) architecture, widely used to predict water resource variables. MLP is one of the best algorithms to capture the non-linear relationships present among the model parameters (Ramchoun et al., 2019). It has been successfully applied in case studies related to river flow forecasting problems (Hussain \& Khan, 2020), chlorophyll studies using RS data (Zhan et al., 2003), and in WQ prediction models (Ahmed et al., 2019). It is an extended version of a simple perceptron, constructed with three layers: input, hidden, and output layers (Fig. 4. It includes many artificial neurons that process the information. The input represented as $\mathrm{Xj}$ are connected to a neuron with its synaptic weight Wj. Mathematically this can be expressed as follows (Hussain \& Khan, 2020).

$$
\begin{gathered}
V i=\sum_{j=0}^{n} \mathrm{WjXj} \\
y i=\phi(V i-\imath)
\end{gathered}
$$

Where, $X j(j=1, \ldots, n)-$ Inputs

$\mathrm{Wj}(\mathrm{j}=1, \ldots ., \mathrm{n})-$ Synaptic weights

$\mathrm{Vi}$ - the weighted sum of inputs to neuron $\mathrm{i}$,

$\Phi$ - Activation function,

i - Threshold value, and 
yi - Output of the neuron i (Ay \& Kisi, 2014).

Each input is weighted with a proper W. The added sum of these weighted inputs and bias forms an input to transfer function (f). The neurons can use any differentiable transfer function to form their outputs. The weights assigned initially are then progressively corrected during the training phase (Tian et al., 2020). MLP is working on the principle of learning the problem-solving process for reaching the Output through understanding the implicit connection between input and Output. However, MLPs still suffer, trapped in a local minimum during its training phase, which never converges to an acceptable error (Zhan et al., 2003). Secondly, it is not easy to set the finest architecture of MLPs with optimum hidden layers, nodes and other hyperparameters controlling the model performance. Thirdly, it is highly susceptible to overfit during the training phase.

\section{Feature Selection for XGBoost and MLP}

Feature selection is the primary focus of any $M L$ model to remove the non-informative or redundant predictors from the model. Because adding unwanted variables to the model will reduce the generalization and overall accuracy of any model, moreover, increase the complexity. Pearson's correlation coefficient technique is applied to examine the correlation between WQPs and RS band/band combinations. Pearson's correlation coefficient is a method for analyzing the close relationship between two variables. It is the quotient of the covariance and the standard deviation between two variables. The correlation of two random variables can be well measured based on covariance.

\section{Hyperparameter Optimization (HPO)}

Hyper Parameters (HP) of any model cannot be estimated by the model using the available data. HPO is the procedure to identify the best combination of HPs that maximize the model performance. Identifying the best combination of HPs for any problem with chosen model manually is a tedious task. We could use the trial and error method by switching to different HPs or copying some values used in some of the other similar works and so forth. It is the process that controls the model learning and results in precise results. Nevertheless, selecting the best pair of HPs is often cannot achieve quickly. HPs can be adjusted by manual tuning or by automated tuning, and the former is time-consuming. This study has applied Automated tuning methods such as Optuna and GridsearchCV for XGBoost and MLP regressor, respectively.

Hyperparameter optimization for XGBoost using Optuna

The software Optuna is used to automate the process of optimization using different algorithms such as Grid search, Random, Bayesian, and Evolutionary algorithms. Using the historical trial spaces, it uncovers the area promising for the search. These advantages of Optuna makes the process of optimizing the HPs easier and less time-consuming. The pruning operation in Optuna discard the results that are not promising at the early stage of the training process, and hence computing time can be saved.

\section{Hyperparameter optimization for MLP regressor using GridsearchCV}

The traditional way of performing HPO is by thoroughly searching inside a learning algorithm's specified subset of HPs space. A grid search algorithm must be guided by some performance metric, typically measured by cross-validation on the training set or evaluation on a held-out validation set. Since the parameter space of a machine learner may include realvalued or unbounded value spaces for specific parameters, manually set bounds and discretization may be necessary before applying grid search. Grid search is arguably the most basic HPs tuning method. With this technique, we simply build a model for each possible combination of all of the HPs values provided, evaluate each model, and select the architecture that produces the best results. We applied the HPs such as Hidden_layer_size, activation, solver, learning_rate and early stopping on different MLP regressor based WQ models. In some cases, this was modified based on the model results.

Grid search searches for the best HP values by recording the performance metrics on each run and identifying the HPs responsible for the optimum model. It can be performed using this package provided in sklearn with a procedure for the 


\section{Result And Discussions}

Optically active and non-active WQPs from satellite data were modelled by applying XGBoost and MLP regressor with each cluster (Table 2) for 2014-2018. Consequently, spatiotemporal maps showing the distribution of different WQPs were generated for the basin showing the measured and predicted values.

\section{In-situ WQPs}

The WQ data collected were preprocessed to overcome the missing values and identify the outliers. All the preprocessing steps were conducted in Python, the scikit-learn library under sklearn.preprocessing. The in-situ data selected were treated for z-transformation in scipy's stats library as these variables were in different scales and units. Summary of basic statistics on different WQPs along all the clusters are presented in Table 3. Box and whisker plots for WQPs along different clusters are plotted to identify the outliers present in the data.

Table 3

Summary of basic statistics for C-0 from 2014-2018

\begin{tabular}{|c|c|c|c|c|c|c|c|c|}
\hline Statistics & $\begin{array}{l}\text { EC_GEN } \\
(\mu \mathrm{mho} / \mathrm{cm})\end{array}$ & $\begin{array}{l}\text { pH_GEN (pH } \\
\text { units) }\end{array}$ & $\begin{array}{l}\text { TDS } \\
(\mathrm{mg} / \mathrm{l})\end{array}$ & $\begin{array}{l}\text { Temp } \\
(\operatorname{deg} C)\end{array}$ & $\begin{array}{l}\mathrm{Ca} \\
(\mathrm{mg} / \mathrm{l})\end{array}$ & $\begin{array}{l}\mathrm{SiO} 2 \\
(\mathrm{mg} / \mathrm{l})\end{array}$ & $\begin{array}{l}\text { BOD } \\
(\mathrm{mg} / \mathrm{l})\end{array}$ & $\begin{array}{l}\mathrm{DO} \\
(\mathrm{mg} / \mathrm{l})\end{array}$ \\
\hline count & 159 & 159 & 159 & 159 & 159 & 159 & 159 & 159 \\
\hline mean & 226.80 & 7.83 & 176.93 & 21.94 & 33.27 & 8.12 & 2.38 & 7.26 \\
\hline std & 59.96 & 0.48 & 22.46 & 3.97 & 7.98 & 0.76 & 0.64 & 0.71 \\
\hline $\min$ & 116.00 & 2.70 & 119.53 & 11.00 & 17.60 & 6.10 & 0.90 & 3.70 \\
\hline $25 \%$ & 180.00 & 7.70 & 166.31 & 19.00 & 28.50 & 7.65 & 2.00 & 6.90 \\
\hline $50 \%$ & 230.00 & 7.90 & 179.50 & 22.50 & 33.70 & 8.20 & 2.50 & 7.30 \\
\hline $75 \%$ & 260.00 & 8.00 & 191.54 & 25.00 & 37.50 & 8.60 & 2.70 & 7.60 \\
\hline $\max$ & 430.00 & 8.40 & 239.32 & 30.50 & 59.50 & 9.80 & 6.30 & 8.80 \\
\hline
\end{tabular}

The correlation matrix calculated using the Pearson correlation method is presented in Table 4. From the proposed correlation matrix, we can see that all the WQPs are positively correlated except EC, which negatively correlates all the WQPs. A strong correlation of $<0.80$ is observed between pH-DO, SiO2-DO, Temp-DO, SiO2-pH and a moderate to less correlation with other WQPs. 
Table 4

Correlation between WQPs in Cluster0

\begin{tabular}{|lllllllll|}
\hline & EC_GEN & pH_GEN & TDS & Temp & Ca & SiO2 & BOD & DO \\
\hline EC_GEN & 1 & -0.74 & -1.00 & -0.65 & -0.62 & -0.79 & -0.26 & -0.61 \\
\hline pH_GEN & -0.74 & 1 & 0.73 & 0.68 & 0.36 & 0.87 & 0.50 & 0.89 \\
\hline TDS & -1.00 & 0.73 & 1 & 0.63 & 0.58 & 0.78 & 0.26 & 0.61 \\
\hline Temp & -0.65 & 0.68 & 0.63 & 1 & 0.35 & 0.63 & 0.34 & 0.86 \\
\hline Ca & -0.62 & 0.36 & 0.58 & 0.35 & 1 & 0.56 & 0.07 & 0.20 \\
\hline SiO2 & -0.79 & 0.87 & 0.78 & 0.63 & 0.56 & 1 & 0.28 & 0.77 \\
\hline BOD & -0.26 & 0.50 & 0.26 & 0.34 & 0.07 & 0.28 & 1 & 0.42 \\
\hline DO & -0.61 & 0.89 & 0.61 & 0.86 & 0.20 & 0.77 & 0.42 & 1 \\
\hline
\end{tabular}

Feature selection criteria on different Clusters

Statistical tests were performed on extracted Rrf data from the respective sampling station to check the inconsistency, and outliers were later corrected by applying a z-score (Sudheer et al., 2007). The Pearson correlation matrix (R) between various Landsat-8 Rrf values on different bands and band ratios with WQPs is studied for all the clusters to select the best features for the modelling, presented for Cluster 0 in Table5. In this study, multispectral bands and their combinations with correlation (i.e. $r \geq 0.50$ ) were identified to shape the input layer (Hafeez et al., 2019; Sharaf El-Din et al., 2017). The reasonable correlation is then identified based on the significance test. A maximum of $50 \%$ significance level or $p<0.05$ is considered to finalize the input parameters (Abdelmalik, 2018; Nas et al., 2010; Swain \& Sahoo, 2017).

Table 5

Cluster-0 Pearson correlation

\begin{tabular}{|c|c|c|c|c|c|c|c|c|c|c|c|c|c|c|}
\hline & B1 & B2 & B3 & B4 & B5 & B6 & B7 & EC & $\mathrm{PH}$ & TDS & Temp & $\mathrm{CA}$ & $\mathrm{SiO} 2$ & DO \\
\hline B1 & 1 & & & & & & & & & & & & & \\
\hline B2 & 0.99 & 1 & & & & & & & & & & & & \\
\hline B3 & 0.95 & 0.96 & 1 & & & & & & & & & & & \\
\hline B4 & 0.86 & 0.89 & 0.94 & 1 & & & & & & & & & & \\
\hline B5 & 0.29 & 0.29 & 0.36 & 0.49 & 1 & & & & & & & & & \\
\hline B6 & 0.16 & 0.16 & 0.16 & 0.33 & 0.85 & 1 & & & & & & & & \\
\hline B7 & 0.16 & 0.16 & 0.14 & 0.32 & 0.76 & 0.98 & 1 & & & & & & & \\
\hline EC & -0.55 & -0.54 & -0.62 & -0.53 & -0.10 & 0.03 & 0.06 & 1 & & & & & & \\
\hline $\mathrm{PH}$ & 0.53 & 0.51 & 0.63 & 0.51 & 0.18 & 0.04 & 0.01 & -0.74 & 1 & & & & & \\
\hline TDS & 0.54 & 0.53 & 0.60 & 0.57 & 0.09 & -0.03 & -0.05 & -1.00 & 0.73 & 1 & & & & \\
\hline Temp & 0.57 & 0.56 & 0.62 & 0.53 & 0.28 & 0.15 & 0.13 & -0.65 & 0.68 & 0.63 & 1 & & & \\
\hline $\mathrm{Ca}$ & 0.32 & 0.32 & 0.36 & 0.25 & 0.06 & -0.13 & -0.18 & -0.62 & 0.36 & 0.58 & 0.35 & 1 & & \\
\hline $\mathrm{SiO} 2$ & 0.53 & 0.52 & 0.62 & 0.51 & 0.19 & 0.05 & 0.01 & -0.79 & 0.87 & 0.78 & 0.63 & 0.56 & 1 & \\
\hline DO & 0.57 & 0.60 & 0.68 & 0.74 & 0.65 & 0.04 & 0.01 & -0.61 & 0.89 & 0.61 & 0.56 & 0.20 & 0.77 & 1 \\
\hline
\end{tabular}


As presented in Table 5 (for Cluster-0), except for Ca, we can observe a significant $(\mathrm{p}<0.05)$ correlation of WQPs with bands B1-B4, a similar trend has been experienced with other clusters as well. However, the remaining bands of Landsat-8 or their combinations such as Cirrus, TIR 1 and 2 had a lesser correlation (i.e. $r<0.50$ ) within the WQPs. As Thermal Infrared 1, 2 were mainly designed to measure the surface temperatures, and on the other hand, Cirrus is commonly used for detecting clouds, this could be the reason we are witnessing a less $r$ value. To improve the relationship between input and output variables for the ML algorithm, we created many band combinations with significant correlations with WQPs. The selection criteria for the features on different clusters are explained below. Cluster-0 is located to the downstream side of the study area and closer to other stations. From the visual interpretation of Google Earth Engine (GEE) satellite images, we could see agriculture and barren land near the sampling stations. At the same time, Cluster-2 to the upstream eastern side of the study area consists of agriculture, barren land with high to moderate (Ayodhya and Basti) of the urban area. Eliginbridge, Balrampur, Ayodhya, Basti, Birdghat, Turtipar are the six sampling stations present in Cluster-2. However, due to the unavailability of Landsat- 8 data for Blarampur, which is omitted from the study. The sampling stations belong Cluster- 0 and Cluster-2 are not showing any seasonal variations, as they belong to the same clusters during dry and wet seasons.

Therefore, the analysis was carried out by combining all stations for both seasons. Cluster- 1 and Cluster- 3 shows a fluctuating seasonal trend and is spread spatially upstream to downstream along the basin. The heavy settlements area is identified through the GEE visual interpretation near Kanpur, Lucknow, Allahabad, and Varanasi (Vinod et al., 2013). A seasonal shifting of sampling stations belonging to Cluster-1 in the dry season to Cluster-3 in the wet season and vice versa was identified in our previous study. While the availability of Landsat-8 data during the wet season $(<50 \%)$, the study was restricted to Dry season (Nov- May) for Cluster-1 \&3.

The correlation coefficient based on the Pearson correlation technique and the Gini importance based ExtraTreesRegressor has been able to identify the best correlated (above 0.50$)$ and significant $(p<0.05)$ bands and band combination for the model input. A total of 166 input parameters (not presented here due to space constraints), including bands and their different combinations, are identified for different clusters and finalized WQPs (Temp, EC, pH, SiO2, and DO). A correlation of 0.567-0.923 is observed on different combinations with a significance of $p<0.05$. Feature importance scores identified through ExtraTreeRegressor are plotted for features based on the Gini importance on various combinations. The same procedure is then repeated for the feature selection process on different clusters. Feature scores for EC along Cluster-0 and pH along Cluster-1 and Cluster-3 are presented in Fig. 5 and Fig. 6a \& b, respectively. A correlation of 0.51-0.89 were observed with different bands and band combinations along Cluster-1 \&3.

\section{Hyperparameter optimization (HPO) for XGBoost}

XGBoost Regressor with Optuna is the HPO algorithm applied in this study. As discussed above, the model was executed using the selected features and target values evaluated separately for each cluster. The performance of these models was assessed in terms of the standard statistical indices like $\mathrm{R}^{2}$, adjusted $\mathrm{R}$ Square and Root Mean Square Error (RMSE). Key results from the study for each cluster are discussed in the below sections.

The XGBoost models are developed using a scikit-learn compatible API. The database for the model is first converted into an optimized data structure called Dmatrix, as this is the specific format that XGBoost can handle. HPs are optimized by applying Optuna. Published under MIT license (https://github.com/ pfnet/optuna/), it is automatic optimization software designed with a define-by-run technique (Akiba et al., 2019). This technique allows the programmer to construct the search space dynamically. Optuna utilizes the historical data to identify the promising search area to optimize the HPs in a minimum amount of time. XGBoost has almost half a dozen HPs. We have applied learning rate, max_depth, I1_reg (L1 regularization term on weights), I2_reg (L2 regularization term on weights) and n_estimators as HPs. The unpraised trails can be controlled through the pruning feature at the beginning of the training phase. We considered one WQPs at a time as Output because the best features identified for these were different. Although, the same HPs are applied in all clusters, within the WQPs and across the clusters. The optimized HPs are displayed in Table 6. 
Table 6

Optimized HPs for different WQPs along different Clusters in XGBoost

\begin{tabular}{|c|c|c|c|c|c|}
\hline Clusters & WQPs & Learning Rate & Max_depth & |1_reg & 12_reg \\
\hline \multirow[t]{5}{*}{$\mathrm{CO}$} & EC & 0.2926042 & 7 & 0.001134 & 0.01710109 \\
\hline & $\mathrm{pH}$ & 0.237338 & 4 & 0.2236841 & 0.00059588 \\
\hline & Temp & 0.205234461 & 8 & 0.0115554 & 2.8569528 \\
\hline & $\mathrm{SiO} 2$ & 0.11117548 & 7 & 0.0038749 & 0.92009494 \\
\hline & Do & 0.1492115 & 8 & 0.0001574 & 0.18985823 \\
\hline \multirow[t]{5}{*}{ C1 } & $\mathrm{pH}$ & 0.178377066 & 7 & 0.014976 & 0.00103462 \\
\hline & Temp & 0.114854821 & 7 & 0.0001023 & 0.01760738 \\
\hline & $\mathrm{SiO} 2$ & 0.558027582 & 7 & $3.582 \mathrm{E}-05$ & $9.11 \mathrm{E}-05$ \\
\hline & DO & 0.267273993 & 6 & 0.0034017 & 0.23174842 \\
\hline & TDS & 1.055113332 & 5 & $1.914 \mathrm{E}-05$ & 1.12E-05 \\
\hline \multirow[t]{6}{*}{ C2 } & $\mathrm{EC}$ & 0.03212539 & 8 & 0.0001335 & $1.3344 \mathrm{E}-05$ \\
\hline & $\mathrm{pH}$ & 0.54051175 & 7 & 0.228148 & 0.00035278 \\
\hline & Temp & 0.138631144 & 4 & $6.56 \mathrm{E}-05$ & 0.01605706 \\
\hline & TDS & 0.030726507 & 5 & 4.51E-05 & $1.51 \mathrm{E}-04$ \\
\hline & $\mathrm{SiO} 2$ & 0.084894633 & 4 & 0.0025398 & 9.96E-01 \\
\hline & DO & 0.158258279 & 4 & 0.0054742 & 9.86053923 \\
\hline \multirow[t]{6}{*}{ C3 } & $\mathrm{EC}$ & 0.831185087 & 6 & 0.0001335 & 1.51E-04 \\
\hline & $\mathrm{pH}$ & 0.097761003 & 5 & 0.005306 & 0.09855875 \\
\hline & Temp & 0.114854821 & 7 & 0.0001023 & 0.01760738 \\
\hline & TDS & 1.055113332 & 5 & $1.91 \mathrm{E}-05$ & 1.12E-05 \\
\hline & $\mathrm{SiO} 2$ & 0.558027582 & 7 & 3.58E-05 & $9.11 \mathrm{E}-05$ \\
\hline & DO & 0.480724584 & 5 & 0.3392282 & 0.00656407 \\
\hline
\end{tabular}

Hyperparameter optimization (HPO) for MLP

MLPRegressor is an algorithm under Neural Network (NN)module in scikit-learn to perform regression tasks using a multilayer perceptron. For optimizing the HPs, we applied GridSearchCv. This approach will orderly builts and evaluate the model for each setoff combination for the model parameters present within a specified grid. We applied the HPs mentioned in Table 7 to optimize the best estimator for our study with 3-7-fold cross-validation. The ratio of train:test was changed from 70-80 until the accuracy for both training and testing became the same, or the difference was negligible. This procedure for the HPs search is carried out for all the clusters by taking one WQPs at a time, and the best HPs are identified for all WQPs and different clusters. The identified list of HPs is presented in Table 7. 
Table 7

Optimized HPs for different WQPs along different Clusters in MLP regressor

\begin{tabular}{|c|c|c|c|c|c|}
\hline Clusters & WQPs & Activation & Hidden Layers & Learning Rate & Solver \\
\hline \multirow[t]{5}{*}{$\mathrm{CO}$} & $\mathrm{EC}$ & logistic & $(50,150)$ & Constant & L-BFGS \\
\hline & $\mathrm{pH}$ & identity & $(150,100,50)$ & Constant & L-BFGS \\
\hline & Temp & relu & $(100,50)$ & Constant & L-BFGS \\
\hline & $\mathrm{SiO} 2$ & relu & $(150,100,50)$ & Constant & L-BFGS \\
\hline & Do & relu & $(100,50)$ & Constant & L-BFGS \\
\hline \multirow[t]{5}{*}{ C1 } & $\mathrm{EC}$ & relu & $(150,50,100)$ & Constant & Adam \\
\hline & $\mathrm{pH}$ & relu & $(100,150,50)$ & Constant & L-BFGS \\
\hline & Temp & tanh & $(100)$, & Constant & L-BFGS \\
\hline & $\mathrm{SiO} 2$ & relu & $(150,50,100)$ & Constant & L-BFGS \\
\hline & Do & tanh & $(150,100,50)$ & Constant & L-BFGS \\
\hline \multirow[t]{5}{*}{$\mathrm{C} 2$} & $\mathrm{EC}$ & relu & $(50,100,150)$ & Constant & Adam \\
\hline & $\mathrm{pH}$ & relu & $(100,150,50)$ & Constant & L-BFGS \\
\hline & Temp & $\tanh$ & $(100)$, & Constant & L-BFGS \\
\hline & $\mathrm{SiO} 2$ & relu & $(50,100,150)$ & Constant & L-BFGS \\
\hline & Do & relu & $(100,50,150)$ & Constant & L-BFGS \\
\hline \multirow[t]{5}{*}{ C3 } & $\mathrm{EC}$ & relu & $(50,150,100)$ & Constant & L-BFGS \\
\hline & $\mathrm{pH}$ & relu & $(100,150,50)$ & Constant & L-BFGS \\
\hline & Temp & logistic & $(50)$, & Constant & L-BFGS \\
\hline & $\mathrm{SiO} 2$ & relu & $(100,50,150)$ & Constant & L-BFGS \\
\hline & Do & relu & $(50,150,100)$ & Constant & L-BFGS \\
\hline
\end{tabular}

\section{Evaluation and Comparisons of Results}

The total dataset contained in-situ, and Rrf data were split randomly for $70 \%$ training and $30 \%$ testing set to create XGBoost and MLP regression models. $\mathrm{R}^{2}$, RMSE (Table 8 and 9) and adjusted R for predicted E.C., pH, Temp, SiO2 and DO were calculated, model evaluation for each Clusters separately and are presented in Table 8, respectively. Except for EC, the R2 values for all WQPs were high and close to 1, showing a notable correlation between Rrf data with in-situ observations. The feature of importance from each WQPs along different clusters were studied to identify the best band and combinations. Feature Importance for DO along Cluster-0 is presented in Fig. 7. The developed Landsat-8 based WQ modelling could be highly recommended as a cost-effective and time-saving method for monitoring optically active and non-active WQPs. The coefficients of determination obtained for WQPs like $\mathrm{pH}$, Temp, SiO2 and DO ( $\mathrm{R}^{2}$ ranges from 0.74-0.98) with XGBoost and MLP with a p-value $<0.005$. However, EC performed poorly in all the clusters, with $R^{2}$ ranging from $0.23-0.37$ for XGBoost. Although, comparatively better results are observed in MLP with $\mathrm{R}^{2}$ of 0.78- 0.99 for Cluster-1, Cluster-2 and Cluster-3, except for Cluster- 0 with $R^{2}$ of 0.32 and 0.27 respectively in the training and testing phase. 
Table 8

Regression statistics of XGBoost regressor along different clusters

\begin{tabular}{|c|c|c|c|}
\hline Clusters & WQPs & Train R2 & Test R2 \\
\hline \multirow[t]{5}{*}{$\mathrm{CO}$} & EC & 0.32 & 0.27 \\
\hline & $\mathrm{pH}$ & 0.94 & 0.78 \\
\hline & Temp & 0.88 & 0.73 \\
\hline & $\mathrm{SiO} 2$ & 0.98 & 0.98 \\
\hline & Do & 0.98 & 0.97 \\
\hline \multirow[t]{5}{*}{ C1 } & EC & 0.35 & 0.33 \\
\hline & $\mathrm{pH}$ & 0.74 & 0.74 \\
\hline & Temp & 0.87 & 0.89 \\
\hline & $\mathrm{SiO} 2$ & 0.96 & 0.96 \\
\hline & Do & 0.98 & 0.927 \\
\hline \multirow[t]{5}{*}{ C2 } & EC & 0.23 & 0.21 \\
\hline & $\mathrm{pH}$ & 0.74 & 0.74 \\
\hline & Temp & 0.85 & 0.89 \\
\hline & $\mathrm{SiO} 2$ & 0.97 & 0.97 \\
\hline & Do & 0.97 & 0.90 \\
\hline \multirow[t]{5}{*}{ C3 } & EC & 0.34 & 0.32 \\
\hline & $\mathrm{pH}$ & 0.81 & 0.76 \\
\hline & Temp & 0.87 & 0.90 \\
\hline & $\mathrm{SiO} 2$ & 0.98 & 0.97 \\
\hline & Do & 0.97 & 0.96 \\
\hline
\end{tabular}


Table 9

Regression statistics of MLP regressor along different clusters

\begin{tabular}{|c|c|c|c|}
\hline Clusters & WQPs & $\mathrm{R} 2$ & RMSE \\
\hline \multirow[t]{5}{*}{$\mathrm{CO}$} & EC & 0.37 & $(\mathrm{mg} / \mathrm{l})$ \\
\hline & $\mathrm{pH}$ & 0.89 & $0.06198(\mathrm{mg} / \mathrm{l})$ \\
\hline & Temp & 0.82 & $0.0812(\mathrm{mg} / \mathrm{l})$ \\
\hline & $\mathrm{SiO} 2$ & 0.93 & $0.00426(\mathrm{mg} / \mathrm{l})$ \\
\hline & Do & 0.93 & $0.00595(\mathrm{mg} / \mathrm{l})$ \\
\hline \multirow[t]{5}{*}{ C1 } & EC & 0.27 & \\
\hline & $\mathrm{pH}$ & 0.87 & $0.00535(\mathrm{mg} / \mathrm{l})$ \\
\hline & Temp & 0.93 & 0.00065 \\
\hline & $\mathrm{SiO} 2$ & 0.91 & $0.00472(\mathrm{mg} / \mathrm{l})$ \\
\hline & Do & 0.87 & $0.02724(\mathrm{mg} / \mathrm{l})$ \\
\hline \multirow[t]{5}{*}{ C2 } & EC & 0.23 & $0.13671(\mathrm{mg} / \mathrm{l})$ \\
\hline & $\mathrm{pH}$ & 0.84 & $0.0183(\mathrm{mg} / \mathrm{l})$ \\
\hline & Temp & 0.95 & 0.0023 \\
\hline & $\mathrm{SiO} 2$ & 0.97 & $0.0063(\mathrm{mg} / \mathrm{l})$ \\
\hline & Do & 0.81 & $0.02233(\mathrm{mg} / \mathrm{l})$ \\
\hline \multirow[t]{5}{*}{ C3 } & EC & 0.35 & $0.00001(\mathrm{mg} / \mathrm{l})$ \\
\hline & $\mathrm{pH}$ & 0.87 & $0.00509(\mathrm{mg} / \mathrm{l})$ \\
\hline & Temp & 0.92 & 0.00065 \\
\hline & $\mathrm{SiO} 2$ & 0.92 & $0.00472(\mathrm{mg} / \mathrm{l})$ \\
\hline & Do & 0.82 & $0.02724(\mathrm{mg} / \mathrm{l})$ \\
\hline
\end{tabular}

The performance evaluation measures, scatter and in the testing phase for MLP (Fig. 8A-V) and XGBoost (Fig. 9A-V) for different WQPs along with all Clusters are presented. As similar trends observed in all the clusters, results of $\mathrm{C} 0, \mathrm{C} 2$ in scatter plots and C3 in Box plots are presented here. We can see better performance for XGBoost (R2 in range of 0.88- 0.98) from the displayed scatter plot with all the parameters than MLP (R2 in range of 0.72-0.97). Box plots were generated for observed Vs predicted values of all WQPs along different clusters to compare the observed minimum, maximum, and mean values with the predicted. A minimal difference in mean value is observed across all the Clusters for both models.

\section{Spatial Distribution of WQPs}

From the developed models, spatiotemporal maps were plotted using the predicted values to study the variation trend of WQPs across all the clusters. The map for the year 2017 dry and wet season is presented and discussed here.

The spatial pattern proves that land use modifications and seasonal variation primarily regulated the WQ conditions, which could be witnessed through the spatiotemporal maps. EC is used to address the total concentration of ionized constituents of water. The higher concentration of conductivity along some stretches of river, specifical stations belongs to Cluster-1 and 3 reflects the higher water pollution. GRB shows high concentrations of EC than the recommended value of $3000 \mu \mathrm{S} / \mathrm{cm}$ along the basin (CWC and NRSC 2014). The typical value of EC can be $300 \mu \mathrm{S} / \mathrm{cm}$ (Bhuyan et al., 2018). The concentration 
of EC along different clusters has not shown a significant seasonal shift for 2017 (Fig. 10A \& B). The values are in the range of $190-600 \mu \mathrm{S} / \mathrm{cm}$ and $150-340 \mu \mathrm{S} / \mathrm{cm}$ in the dry and wet seasons, respectively. Thus, showing an increase in the dry season. Although, no seasonal trend is observed. Lesser value of EC is observed in Cluster-0 and 2 for the dry season. As per WHO, the permissible limits of EC for drinking water purposes should be $1500 \mu \mathrm{mhos} / \mathrm{cm}$ (WHO 1996). Except for the difference in the value range, no serious spatio-temporal change in the patterns was detected in Dry and Wet seasons. The high concentrations are marked in Lucknow, Allahabad Varanasi and nearby stations along Cluster-1 and 3. These higher concentrations of EC could be accredited to heavy anthropogenic activities like agricultural and urban runoff (GEE Images).

As per IS IS:2296 specification, the permissible range for $\mathrm{pH}$ is 6.5- 8.5. Primarily, $\mathrm{pH}$ ranges from 6.5 to 9 are convenient for the survival of the aquatic ecosystem (CWC and NRSC 2014). A slight variation in values is observed in both seasons (Fig. 10C \& D). Keeping the aquatic ecosystem within this range is crucial, as high/low pH values can be disastrous to the ecosystem (Al-Badaii et al., 2013). This work observed stable pH values and all clusters in different seasons ranging from 7.2-8.5, which falls within the permissible limits.

WT along the basin for the state of UP ranges from 16 to $46^{\circ} \mathrm{C}$. WT has a strong correlation with salinity, toxic absorption and DO. It also controls the rate of photosynthesis of aquatic plants. Human interactions such as agricultural and industrial runoff and deforestation pose a significant variation in WT and eventually reduce the DO value. Therefore, significant variation in DO and WT constitutes a greater threat to the aquatic ecosystem. The inverse correlation between WT and DO is a natural exercise, and high water temperature makes water saturated with oxygen, hence holding lesser DO (Bhat et al., 2014; Lamaro et al., 2013). As presented in Fig. 10E \& F, a clear seasonal and temporal shift in WT is observed in all years, especially along the middle stream of the basin. The values were ranged from $14-25^{\circ} \mathrm{C}$ and $24-32^{\circ} \mathrm{C}$ on dry and wet seasons, respectively.

Downstream of the study area has shown high values of TDS for Dry and Wet season $216.96-285 \mathrm{mg} / \mathrm{l}$ and $231.281 \mathrm{mg} / \mathrm{l}$ respectively (Fig. 10G \& H). Some of the stations located in Cluster-1 and 3 along the upstream side of the study area showed a seasonal shift, falling to minimum range of $132-181 \mathrm{mg} / \mathrm{l}$ from $150-195 \mathrm{mg} / \mathrm{l}$ for both the seasons. A similar spatiotemporal trend is observed for the other years considered in this study. The permissible values of TDS as per IS:2296 are (ClassA-500, ClassC-1500 and ClassE0-2100 mg/l). The predicted values of 2017 in both seasons are well within limits. The higher value of TDS indicates the presence of high anthropogenic activities and runoff with heavy suspended matter loading.

Not much seasonal changes are witnessed for SiO2, with values ranging from $5.00-11.36 \mathrm{mg} / \mathrm{l}$ for both seasons (Fig. $10 \mathrm{l} \&$ J).

Nearly most of the sampling site has recorded a DO value above $5 \mathrm{mg} / \mathrm{L}$ (Dutta et al., 2020), which is permissible for bathing as per IS:2296. This fluctuation in DO could be linked to the waste discharge from various non-point sources, increase in WT and biological activities of aquatic organisms along the river basin. Most stations in Cluster-2 and C3 shows a clear seasonal shift. The minimum value is in the range of 5.50-5.8, 5.70-5.93 mg/l in dry and wet seasons. The stations Kanpur, Lucknow Ankinghat, have followed the same pattern during both seasons with a range of $6.12-7.05 \mathrm{mg} / \mathrm{l}$. While the maximum values of DO observed were (7.67-8.30 mg/l in both seasons) along some stretches of the basin (Fig. 10K \& L).

\section{Conclusion}

In this study, we evaluated six years of satellite data covering geographically upstream to downstream (Ankinghat to Chopan - 20 stations under CWC MGD I and II) for characterizing the trends of dominant WQPs across the four clusters identified in our previous study. We tried to illustrate the presence of a significant empirical association between Landsat-8 data with observed WQPs as explained below: 
1. The demonstrated regression techniques XGBoost and MLP have established the spatial and temporal distribution of dominant WQPs along the basin. Thus, it can be proposed as a rapid, inexpensive, and convenient method for better management to obtain helpful WQ information from satellite data.

2. The applied hyperparameter optimization techniques used on these models have helped achieve optimal hyperparameters. Further, it drastically improved the model performance XGBoost (R2 in range of 0.88- 0.98) and MLP ( ${ }^{2}$ in range of 0.72-0.97), than the model without hyperparameter optimization.

3. The study results recommend that the band ratio technique has more potential to uncover the relationship between WQPS and RS than the single bands as the reflectance ratio bring down and eventually remove the effect of the changes in illumination condition and the sediment type. Moreover, the binary combination factor weakens the influence of particle size on the reflectance value.

4. According to IS:2296 drinking water standards, the predicted values for different WQPs are compared. The high critical values along some stretch of GRB conclude a pressing need to address the contaminated site and alleviate the pollution issues for a sustainable riverine ecosystem.

5. However, the non-availability and the existence of cloud cover of Landsat-8, especially during the wet season, has failed the model to discuss the spatiotemporal trend in some of the stations present in Cluster-1.

6. Given that, future work issues could focus on fusing the Landsat-8 with any other suitable sensor data. Furthermore, it will be constructive to create a more generalized approach for such analysis along GRB and reduce the dependency on traditional water sampling techniques.

\section{Declarations}

\section{Ethics approval and consent to participate}

Not Applicable

\section{Consent for Publication}

Not Applicable

\section{Availability of data materials}

The data supporting this study's findings are available from Central Water Commission (CWC) Middle Ganga Division (MGD I\&II). But restrictions apply to the availability of these data, which were used under license for the current study, and so are not publicly available.

\section{Competing interests}

The authors declare that they have no competing interests

Funding: The authors confirm that no funding sources were involved in this study.

\section{Authors' contributions}

Ashwitha Krishnaraj: Whole work

Dr Ramesh Honnasiddaiah: Corrected and Editing part in the manuscript. 
The Landsat images are downloaded from http://www.earthexplorer.usgs.gov. The water quality data is procured from Central Water Commission (CWC) Middle Ganga Division (MGD I\&II) is acknowledged.

\section{References}

1. Abdelmalik KW (2018a) Role of statistical remote sensing for Inland water quality parameters prediction. Egypt J Remote Sens Space Sci 21(2):193-200. https://doi.org/10.1016/j.ejrs.2016.12.002

2. Ahmed U, Mumtaz R, Anwar H, Shah AA, Irfan R, García-Nieto J (2019) Efficient water quality prediction using supervised machine learning. Water (Switzerland) 11(11):1-14. https://doi.org/10.3390/w11112210

3. Akiba T, Sano S, Yanase T, Ohta T, Koyama M (2019) Optuna: A Next-generation Hyperparameter Optimization Framework. Proceedings of the ACM SIGKDD International Conference on Knowledge Discovery and Data Mining, 2623-2631. https://doi.org/10.1145/3292500.3330701

4. Al-Badaii F, Shuhaimi-Othman M, Gasim MB (2013) Water quality assessment of the Semenyih river, Selangor, Malaysia. Journal of Chemistry. August. https://doi.org/10.1155/2013/871056

5. Allee RJ, Johnson JE (1999) Use of satellite imagery to estimate surface chlorophyll a and secchi disc depth of bull shoals reservoir, arkansas, usa. Int J Remote Sens 20(6):1057-1072. https://doi.org/10.1080/014311699212849

6. Andrzej Urbanski J, Wochna A, Bubak I, Grzybowski W, Lukawska-Matuszewska K, Łącka M, Śliwińska S, Wojtasiewicz B, Zajączkowski M (2016) Application of Landsat 8 imagery to regional-scale assessment of lake water quality. Int J Appl Earth Obs Geoinf 51:28-36. https://doi.org/10.1016/j.jag.2016.04.004

7. Antonini K, Langer M, Farid A, Walter U (2017) SWEET CubeSat - Water detection and water quality monitoring for the 21st century. Acta Astronaut 140:10-17. https://doi.org/10.1016/j.actaastro.2017.07.046

8. Ay M, Kisi O (2014) Modelling of chemical oxygen demand by using ANNs, ANFIS and k-means clustering techniques. J Hydrol 511:279-289. https://doi.org/10.1016/j.jhydrol.2014.01.054

9. Baban SMJ (1993) Detecting water quality parameters in the norfolk broads, U.K., using landsat imagery. Int J Remote Sens 14(7):1247-1267. https://doi.org/10.1080/01431169308953955

10. Bay F, Remote U, Gholizadeh MH, Melesse AM (2017) Journal of Remote Sensing \& GIS Study on Spatiotemporal Variability of Water Quality Parameters in. 6(3). https://doi.org/10.4172/2469-4134

11. Bhat SA, Meraj G, Yaseen S, Pandit AK (2014) Statistical Assessment of Water Quality Parameters for Pollution Source Identification in Sukhnag Stream: An Inflow Stream of Lake Wular (Ramsar Site), Kashmir Himalaya. Journal of Ecosystems, 2014, 1-18. https://doi.org/10.1155/2014/898054

12. Bhuyan MS, Bakar MA, Sharif ASM, Hasan M, Islam MS (2018) Water Quality Assessment Using Water Quality Indicators and Multivariate Analyses of the Old Brahmaputra River. Pollution 4(3):481-493.

https://doi.org/10.22059/poll.2018.246865.350

13. Bonansea M, Ledesma M, Rodriguez C, Pinotti L (2018) Using new remote sensing satellites for assessing water quality in a reservoir. Hydrol Sci J 0(0):1-11. https://doi.org/10.1080/02626667.2018.1552001

14. Bonansea M, Rodriguez MC, Pinotti L, Ferrero S (2015) Using multi-temporal Landsat imagery and linear mixed models for assessing water quality parameters in Río Tercero reservoir (Argentina). Remote Sens Environ 158:28-41. https://doi.org/10.1016/j.rse.2014.10.032

15. Chang N, Bin, Yang YJ, Daranpob A, Jin KR, James T (2012) Spatiotemporal pattern validation of chlorophyll-a concentrations in Lake Okeechobee, Florida, using a comparative MODIS image mining approach. Int J Remote Sens 33(7):2233-2260. https://doi.org/10.1080/01431161.2011.608089

16. Chen F, Xiao D, Li Z (2016) Developing water quality retrieval models with in situ hyperspectral data in Poyang Lake, China. Geo-Spatial Information Science 19(4):255-266. https://doi.org/10.1080/10095020.2016.1258201 
17. Du C, Wang Q, Li Y, Lyu H, Zhu L, Zheng Z, Wen S, Liu G, Guo Y (2018) Estimation of total phosphorus concentration using a water classification method in inland water. Int J Appl Earth Obs Geoinf 71(May):29-42. https://doi.org/10.1016/j.jag.2018.05.007

18. Dutta V, Dubey D, Kumar S (2020) Science of the Total Environment Cleaning the River Ganga: Impact of lockdown on water quality and future implications on river rejuvenation strategies. Sci Total Environ 743:140756. https://doi.org/10.1016/j.scitotenv.2020.140756

19. El Saadi AM, Yousry MM, Jahin HS (2014) Statistical estimation of Rosetta branch water quality using multi-spectral data. Water Science 28(1):18-30. https://doi.org/10.1016/j.wsj.2014.10.001

20. Gange N (2020) Industrial effluent monitoring. available at. https://nmcg.nic.in/ NamamiGanga.aspx

21. Garg V, Aggarwal SP, Chauhan P (2020) Changes in turbidity along Ganga River using Sentinel-2 satellite data during lockdown associated with COVID-19. Geomatics, Natural Hazards and Risk 11(1):1175-1195.

https://doi.org/10.1080/19475705.2020.1782482

22. Garg V, Senthil Kumar A, Aggarwal SP, Kumar V, Dhote PR, Thakur PK, Nikam BR, Sambare RS, Siddiqui A, Muduli PR, Rastogi G (2017) Spectral similarity approach for mapping turbidity of an inland waterbody. J Hydrol 550:527-537. https://doi.org/10.1016/j.jhydrol.2017.05.039

23. Glasgow HB, Burkholder JAM, Reed RE, Lewitus AJ, Kleinman JE (2004) Real-time remote monitoring of water quality: A review of current applications, and advancements in sensor, telemetry, and computing technologies. J Exp Mar Biol Ecol 300(1-2):409-448. https://doi.org/10.1016/j.jembe.2004.02.022

24. González-Márquez LC, Torres-Bejarano FM, Torregroza-Espinosa AC, Hansen-Rodríguez IR, Rodríguez-Gallegos HB (2018) Use of LANDSAT 8 images for depth and water quality assessment of El Guájaro reservoir, Colombia. J S Am Earth Sci 82:231-238. https://doi.org/10.1016/j.jsames.2018.01.004

25. González S, García S, Del Ser J, Rokach L, Herrera F (2020) A practical tutorial on bagging and boosting based ensembles for machine learning: Algorithms, software tools, performance study, practical perspectives and opportunities. Information Fusion 64(July):205-237. https://doi.org/10.1016/j.inffus.2020.07.007

26. Hafeez S, Wong M, Ho H, Nazeer M, Nichol J, Abbas S, Tang D, Lee K, Pun L (2019) Comparison of Machine Learning Algorithms for Retrieval of Water Quality Indicators in Case-II Waters: A Case Study of Hong Kong. Remote Sensing 11(6):617. https://doi.org/10.3390/rs11060617

27. Haji Gholizadeh M, Melesse AM, Reddi L (2016) Spaceborne and airborne sensors in water quality assessment. Int J Remote Sens 37(14):3143-3180. https://doi.org/10.1080/01431161.2016.1190477

28. Hussain D, Khan AA (2020) Machine learning techniques for monthly river flow forecasting of Hunza River, Pakistan. Earth Sci Inf 13(3):939-949. https://doi.org/10.1007/s12145-020-00450-z

29. Ibrahem A, Osman A, Najah A, Fai M, Feng Y, El-shafie A (2021) Extreme gradient boosting (Xgboost) model to predict the groundwater levels in Selangor Malaysia.Ain Shams Engineering

Journa/ https://doi.org/10.1016/j.asej.2020.11.011

30. Clay D, Barrett, Amy E, Frazier (2016) Automated Method for Monitoring Water Quality Using Landsat Imagery. Water, 8(257). http://doi:10.3390/w8060257

31. Kiangala SK, Wang Z (2021) An effective adaptive customization framework for small manufacturing plants using extreme gradient boosting-XGBoost and random forest ensemble learning algorithms in an Industry 4.0 environment. Machine Learning with Applications, 4(December 2020), 100024. https://doi.org/10.1016/j.mlwa.2021.100024

32. Koponen S, Pulliainen J, Kallio K, Hallikainen M (2002) Lake water quality classification with airborne hyperspectral spectrometer and simulated MERIS data. 79, 51-59

33. Lamaro AA, Mariñelarena A, Torrusio SE, Sala SE (2013) Water surface temperature estimation from Landsat 7 ETM+ thermal infrared data using the generalized single-channel method: Case study of Embalse del Río Tercero (Córdoba, Argentina). Adv Space Res 51(3):492-500. https://doi.org/10.1016/j.asr.2012.09.032

Page $18 / 26$ 
34. Li Y, He L, Peng B, Fan K, Tong L (2018) Remote sensing inversion of water quality parameters in longquan lake based on PSO-SVR algorithm. International Geoscience and Remote Sensing Symposium (IGARSS), 2018-July(Fig. 1), 92689271. https://doi.org/10.1109/IGARSS.2018.8517937

35. Liu J, Zhang Y, Yuan D, Song X (2015) Empirical Estimation of Total Nitrogen and Total Phosphorus Concentration of Urban Water Bodies in China Using High Resolution IKONOS Multispectral Imagery. Water 7(12):6551-6573. https://doi.org/10.3390/w7116551

36. Lounis B, Aissa AB, Rabia S, Ramoul A (2013) Hybridisation of fuzzy systems and genetic algorithms for water quality characterisation using remote sensing data. International Journal of Image and Data Fusion 4(2):171-196. https://doi.org/10.1080/19479832.2011.617318

37. Nas B, Ekercin S, Karabörk H, Berktay A, Mulla DJ (2010) An application of landsat-5TM image data for water quality mapping in Lake Beysehir, Turkey. Water Air Soil Pollut 212(1-4):183-197. https://doi.org/10.1007/s11270-010-03312

38. Natekin A, Knoll A (2013) Gradient boosting machines, a tutorial. Frontiers in Neurorobotics, 7(DEC). https://doi.org/10.3389/fnbot.2013.00021

39. Nguyen TT, Keupers I, Willems P (2018) Conceptual river water quality model with flexible model structure. Environ Model Softw 104:102-117. https://doi.org/10.1016/j.envsoft.2018.03.014

40. Olmanson LG, Brezonik PL, Bauer ME (2013) Remote Sensing of Environment Airborne hyperspectral remote sensing to assess spatial distribution of water quality characteristics in large rivers: The Mississippi River and its tributaries in Minnesota. Remote Sens Environ 130:254-265. https://doi.org/10.1016/j.rse.2012.11.023

41. Panda SS, Garg V, Chaubey I (2004) Artificial Neural Networks Application in Lake Water Quality Estimation Using Satellite Imagery 4(2):65-74

42. Profiles M (ed) Meta-XGBoost for Hyperspectral Image Classification Using Extended MSER-Guided Morphological Profiles

43. Ramchoun H, Janati Idrissi MA, Ghanou Y, Ettaouil M (2019) Multilayer perceptron new method for selecting the architecture based on the choice of different activation functions. International Journal of Information Systems in the Service Sector 11(4):21-34. https://doi.org/10.4018/IJISSS.2019100102

44. River G, Management B (2013) Demographic and Analysis in Middle Ganga Basin. 1-88

45. Din SE, Zhang E, Suliman A (2017) Mapping concentrations of surface water quality parameters using a novel remote sensing and artificial intelligence framework. Int J Remote Sens 38(4):1023-1042.

https://doi.org/10.1080/01431161.2016.1275056

46. Song K, Liu G, Wang Q, Wen Z, Lyu L, Du Y, Sha L, Fang C (2020) Quantification of lake clarity in China using Landsat OLI imagery data. Remote Sens Environ 243(March):111800. https://doi.org/10.1016/j.rse.2020.111800

47. Sudheer KP, Chaubey I, Garg V (2007) Lake Water Quality Assessment From Landsat Thematic Mapper Data Using Neural Network: An Approach To Optimal Band Combination Selection. Journal Of The American Water Resources Agociation American Water Resources Association 1. 72701

48. Swain R, Sahoo B (2017) Improving river water quality monitoring using satellite data products and a genetic algorithm processing approach. Sustainability of Water Quality and Ecology 9-10:88-114.

https://doi.org/10.1016/j.swaqe.2017.09.001

49. Swain R, Sahoo B (2017) Mapping of heavy metal pollution in river water at daily time-scale using spatio-temporal fusion of MODIS-aqua and Landsat satellite imageries. J Environ Manage 192:1-14.

https://doi.org/10.1016/j.jenvman.2017.01.034

50. Teodoro AC, Veloso-Gomes F, Gonçalves H (2007) Retrieving TSM concentration from multispectral satellite data by multiple regression and artificial neural networks. IEEE Trans Geosci Remote Sens 45(5):1342-1350.

https://doi.org/10.1109/TGRS.2007.893566

Page 19/26 
51. Tian Z, Xiao J, Feng H, Wei Y (2020) Credit Risk Assessment based on Gradient Boosting Decision Tree. Procedia Computer Science 174:150-160. https://doi.org/10.1016/j.procs.2020.06.070

52. Trivedi RC (2010) Water quality of the Ganga River - An overview. Aquatic Ecosystem Health and Management 13(4):347-351. https://doi.org/10.1080/14634988.2010.528740

53. Vander Woerd H, Pasterkamp R (2004) Mapping of the North Sea turbid coastal waters using SeaWiFS data. Can J Remote Sens 30(1):44-53. https://doi.org/10.5589/m03-051

54. Wang X, Yang W (2019) Water quality monitoring and evaluation using remote-sensing techniques in China: A systematic review. Ecosystem Health and Sustainability 5(1):47-56. https://doi.org/10.1080/20964129.2019.1571443

55. Wang X, Ma L, Wang X (2010) Apply semi-supervised support vector regression for remote sensing water quality retrieving. International Geoscience and Remote Sensing Symposium (IGARSS), 2757-2760.

https://doi.org/10.1109/IGARSS.2010.5653832

56. Wen X, Yang X (2009) Monitoring of Water Quality Using Remote Sensing Data Mining

57. Yepez S, Laraque A, Martinez JM, De Sa J, Carrera JM, Castellanos B, Gallay M, Lopez JL (2018) Retrieval of suspended sediment concentrations using Landsat-8 OLI satellite images in the Orinoco River (Venezuela). Comptes Rendus - Geoscience 350(1-2):20-30. https://doi.org/10.1016/j.crte.2017.08.004

58. Zhan H, Shi P, Chen C (2003) Retrieval of oceanic chlorophyll concentration using support vector machines. IEEE Trans Geosci Remote Sens 41:2947-2951. (12 PART II) https://doi.org/10.1109/TGRS.2003.819870

59. Zhang Y, Wu L, Ren H, Deng L, Zhang P (2020) Retrieval of water quality parameters from hyperspectral images using hybrid Bayesian probabilistic neural network. Remote Sensing 12(10):1-31. https://doi.org/10.3390/rs12101567

60. Zhou C, Zhang C, Tian D, Wang K, Huang M, Liu Y (2017) A software sensor model based on hybrid fuzzy neural network for rapid estimation water quality in Guangzhou section of Pearl River, China. Journal of Environmental Science and Health - Part A Toxic/Hazardous Substances and Environmental Engineering, 0(0), 1-8.

https://doi.org/10.1080/10934529.2017.1369815

\section{Figures}




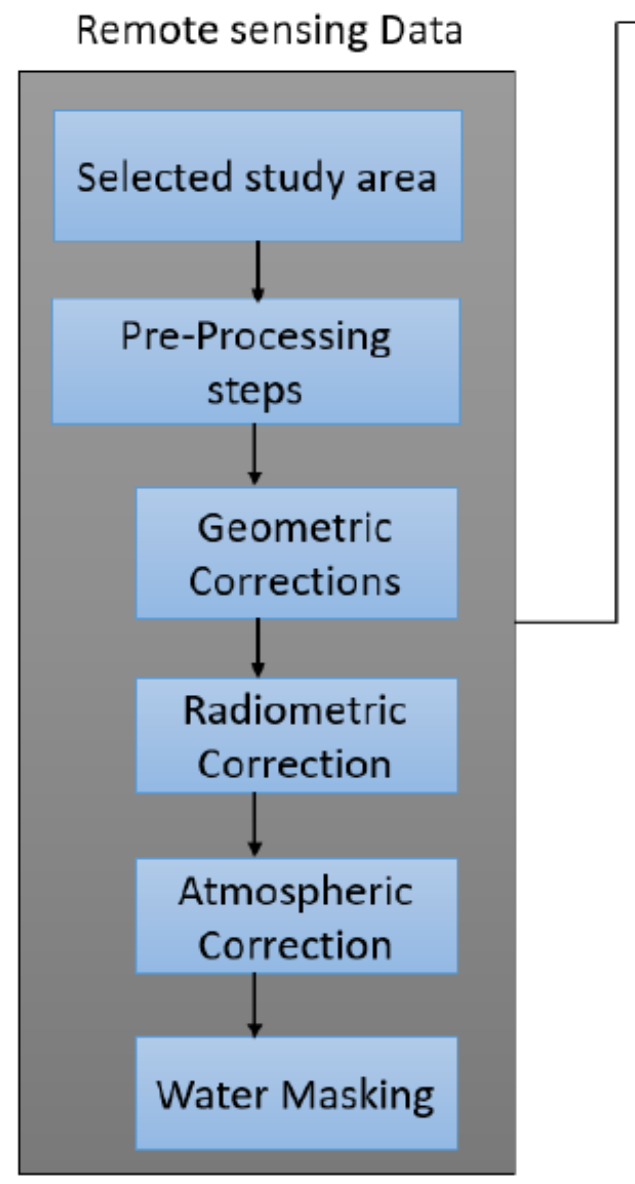

Corrected Spectral information

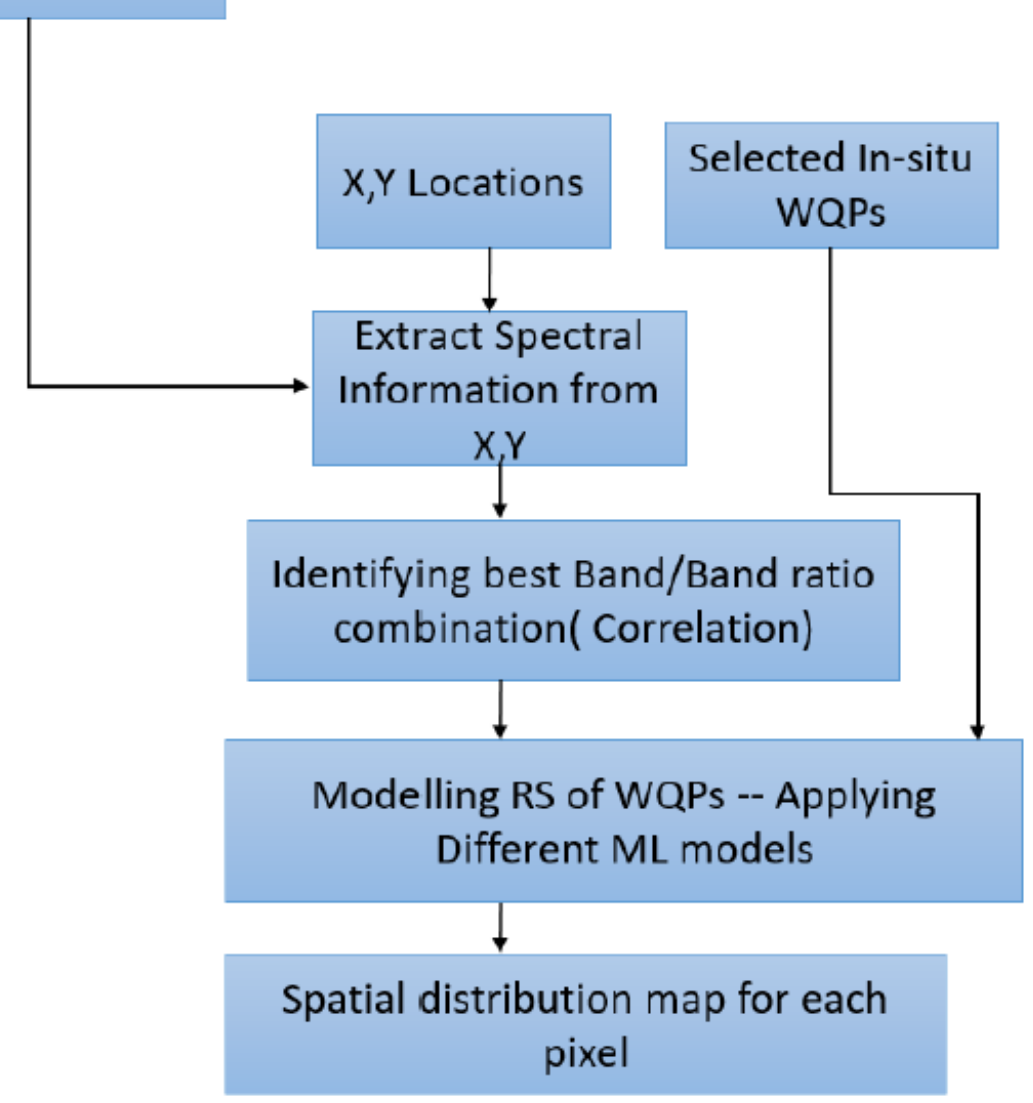

Figure 1

Overall methodology adopted

Figure 2

Geographical Location of the Study area

Figure 3

Different Clusters Identified (Krishnaraj \& Deka, 2020) 


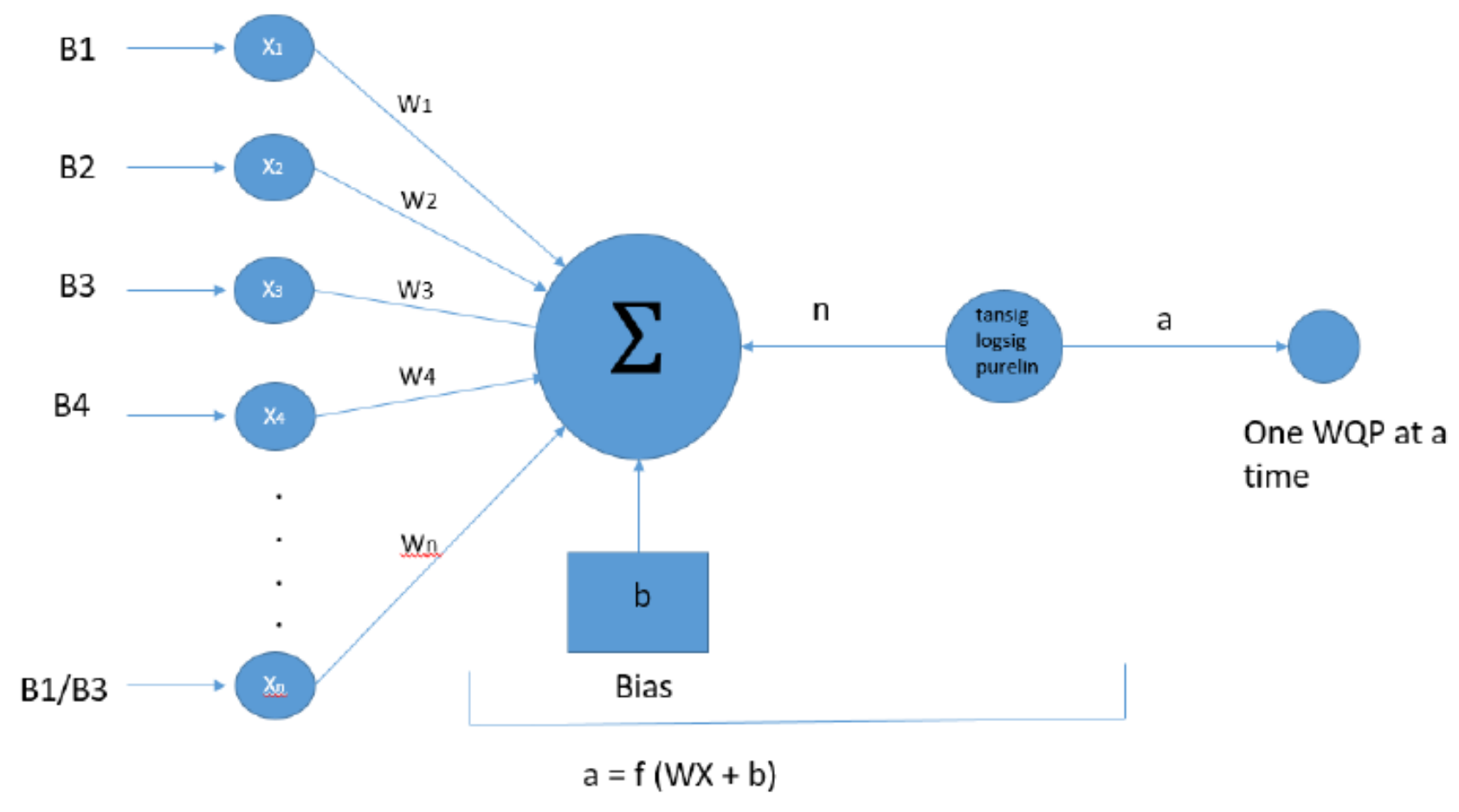

Figure 4

Basic Structure of a Simple MLP Neural Network

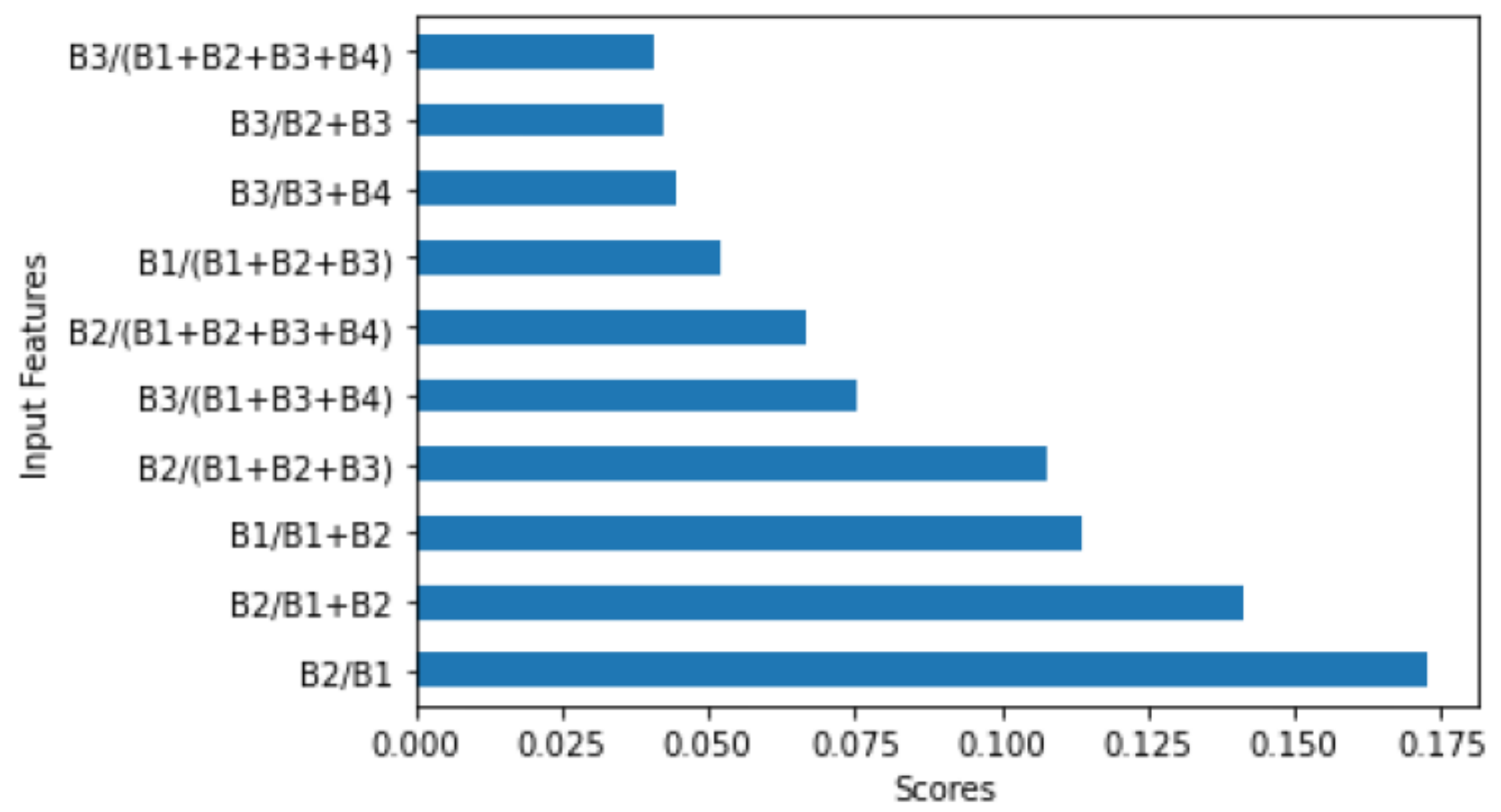

Figure 5

Feature score for different Input parameters for EC along C0 

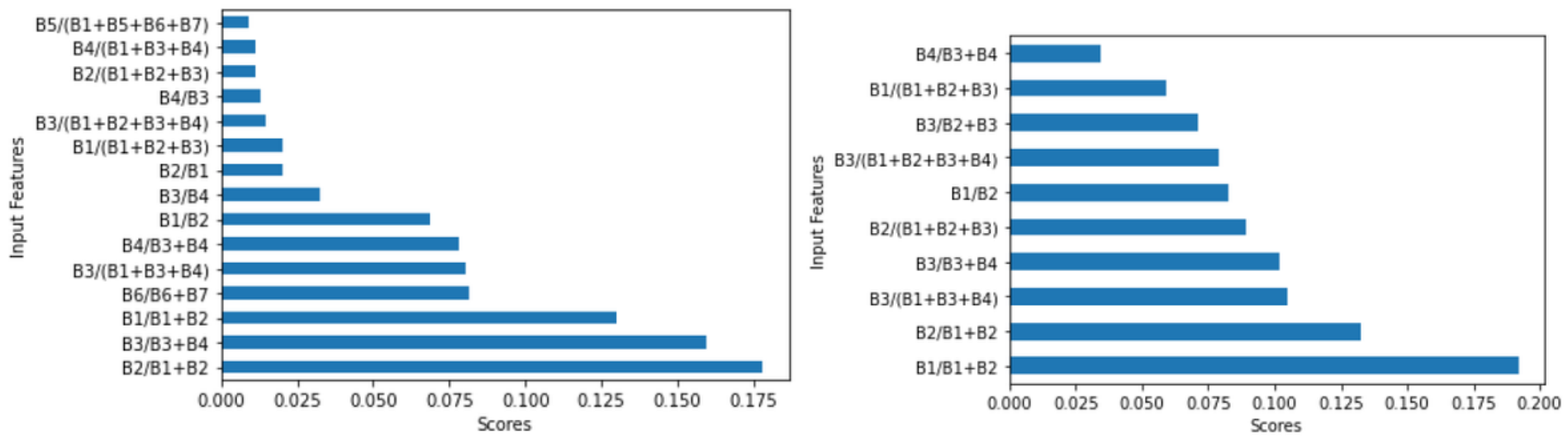

Figure 6

a \&b: Feature score for different Input parameters for $\mathrm{pH}$ along with $\mathrm{C} 1$ and $\mathrm{C} 3$ 


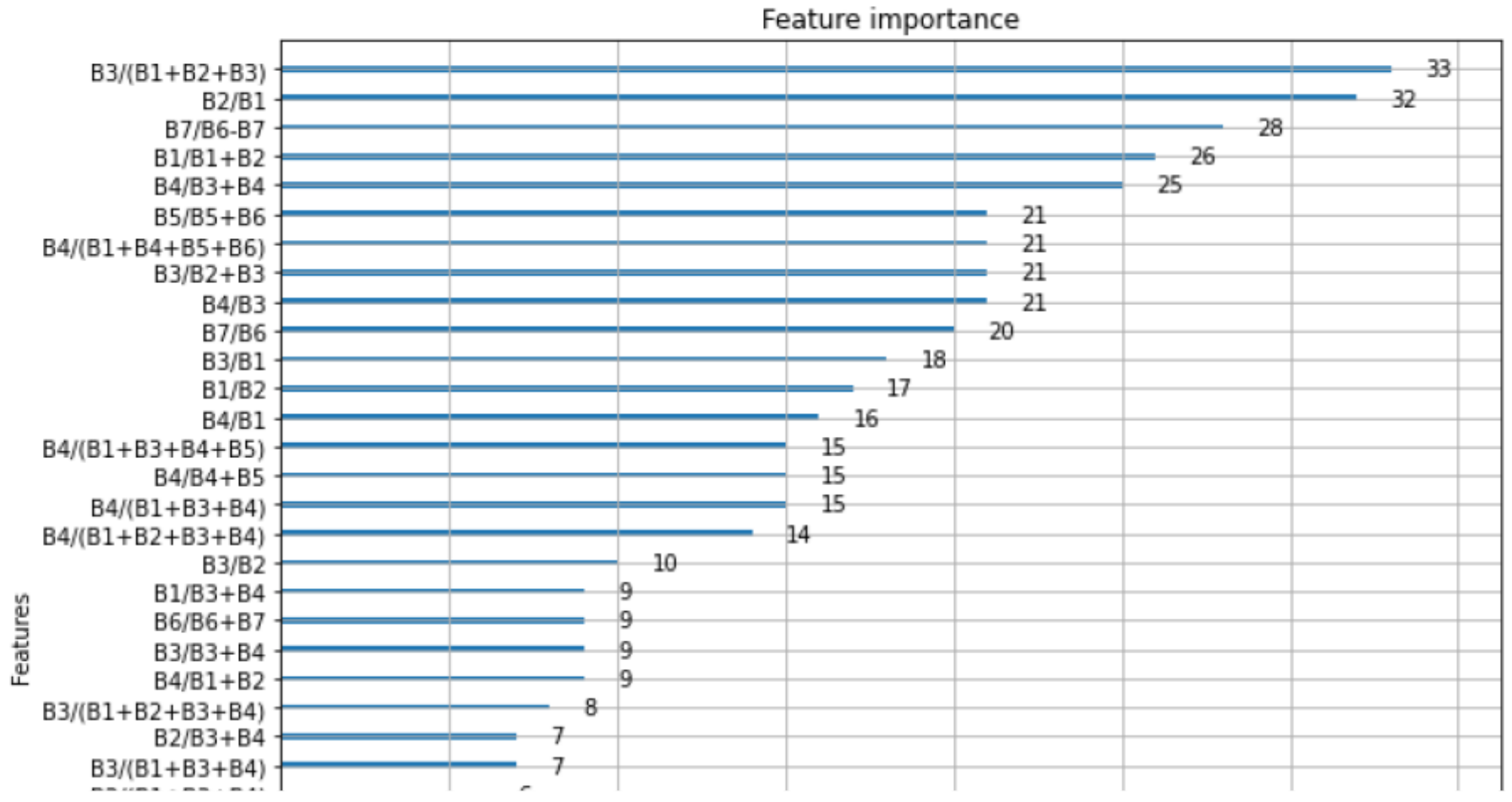

Figure 7

DO CO Feature of Importance 

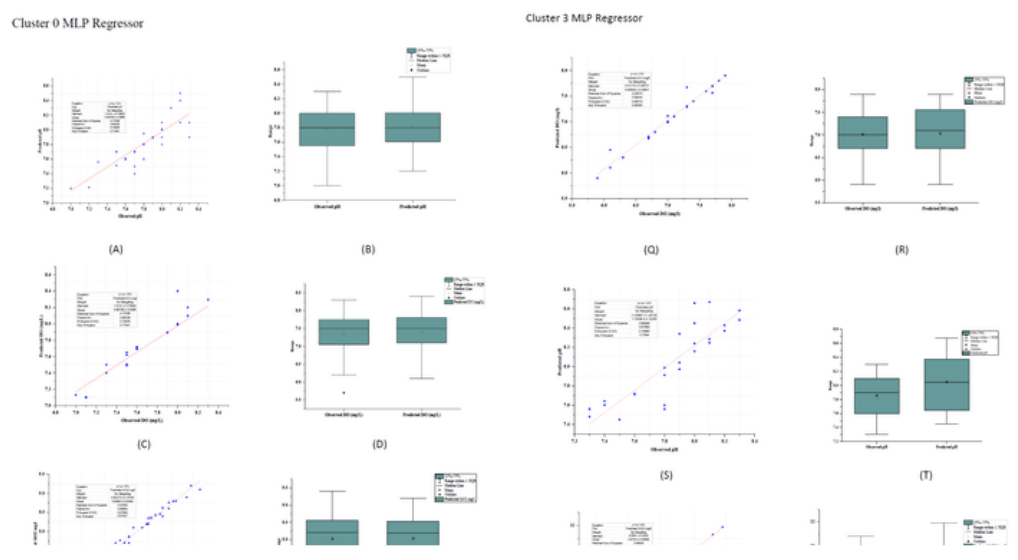

\section{Figure 8}

A-V Performance evaluation for MLP regressor along different clusters

\section{Figure 9}

A-V. Performance evaluation for MLP Regressor along different Clusters

\section{Figure 10}

Spatial distribution map for estimated water quality parameters 
Page 26/26 